This is an electronic reprint of the original article. This reprint may differ from the original in pagination and typographic detail.

\author{
Author(s): Javanainen, Arto; Galloway, Kenneth F.; Ferlet-Cavrois, Veronique; Lauenstein, Jean- \\ Marie; Pintacuda, Francesco; Schrimpf, Ronald D.; Reed, Robert A.; Virtanen, Ari
}

Title: $\quad$ Charge Transport Mechanisms in Heavy-Ion Driven Leakage Current in Silicon Carbide Schottky Power Diodes

Year: $\quad 2016$

Version:

Please cite the original version:

Javanainen, A., Galloway, K. F., Ferlet-Cavrois, V., Lauenstein, J.-M., Pintacuda, F., Schrimpf, R. D., Reed, R. A., \& Virtanen, A. (2016). Charge Transport Mechanisms in Heavy-Ion Driven Leakage Current in Silicon Carbide Schottky Power Diodes. IEEE Transactions on Device and Materials Reliability, 16(2), 208-212.

https://doi.org/10.1109/TDMR.2016.2557585

All material supplied via JYX is protected by copyright and other intellectual property rights, and duplication or sale of all or part of any of the repository collections is not permitted, except that material may be duplicated by you for your research use or educational purposes in electronic or print form. You must obtain permission for any other use. Electronic or print copies may not be offered, whether for sale or otherwise to anyone who is not an authorised user. 


\title{
Charge Transport Mechanisms in Heavy-Ion Driven Leakage Current in Silicon Carbide Schottky Power Diodes
}

\author{
Arto Javanainen, Member, IEEE, Kenneth F. Galloway, Fellow, IEEE, \\ Veronique Ferlet-Cavrois, Fellow, IEEE, Jean-Marie Lauenstein, Member, IEEE, \\ Francesco Pintacuda, Ronald D. Schrimpf, Fellow, IEEE, Robert A. Reed, Fellow, IEEE, \\ and A. Virtanen, Member, IEEE
}

\begin{abstract}
Under heavy-ion exposure at sufficiently high reverse bias voltages silicon carbide (SiC) Schottky diodes are observed to exhibit gradual increases in leakage current with increasing ion fluence. Heavy-ion exposure alters the overall reverse current-voltage characteristics of these diodes, leaving the forward characteristics practically unchanged. This paper discusses the charge transport mechanisms in the heavy-ion damaged SiC Schottky diodes. A macro model, describing the reverse current-voltage characteristics in the degraded $\mathrm{SiC}$ Schottky diodes is proposed.
\end{abstract}

Index Terms - Current-voltage characteristics, Ion radiation effects, Modeling, Power semiconductor devices, Schottky diodes, Silicon carbide

\section{INTRODUCTION}

$\mathrm{S}_{\mathrm{p}}^{\mathrm{n}}$ ILICON CARBIDE (SiC) devices have become attractive for $\checkmark$ power applications both in space and at ground level. Compared to silicon, $\mathrm{SiC}$ is a superior material for power devices with higher breakdown field and thermal conductivity. However, SiC power devices (MOSFETs and diodes) have been observed to be surprisingly vulnerable to particle radiation [1]-[5]. Moreover, SiC Schottky diodes exhibit responses to heavy ions that are not typically observed in

This work was supported by Walter Ahlström Foundation through the Tutkijat Maailmalle program, the European Space Agency (ESA/ESTEC Contract 4000111630/14/NL/PA) and the Academy of Finland under the Finnish Centre of Excellence Programme 2012-2017 (Project No 2513553, Nuclear and Accelerator Based Physics).

A. Javanainen and A. Virtanen are with the University of Jyvaskyla, Department of Physics, P.O. Box 35, FI-40014, University of Jyvaskyla, Finland. (email: arto.javanainen@jyu.fi, ari.j.virtanen@jyu.fi)

A. Javanainen is also with the Electrical Engineering and Computer Science Department, Vanderbilt University, Nashville, TN 37235 USA. (email: arto.javanainen@vanderbilt.edu)

K. Galloway, R. Schrimpf and R. Reed are with the Electrical Engineering and Computer Science Department, Vanderbilt University, Nashville, TN $37235 \quad$ USA. (email: kenneth.f.galloway@vanderbilt.edu, ron.schrimpf@vanderbilt.edu, robert.reed@vanderbilt.edu)

V. Ferlet-Cavrois is with the European Space Agency, ESTEC, 2200 AG Noordwijk, The Netherlands. (email: veronique.ferlet-cavrois@esa.int)

J.-M. Lauenstein is with NASA/GSFC, Code 561.4, Greenbelt, MD 20771 USA. (email: jean.m.lauenstein@nasa.gov)

F. Pintacuda is with the STMicroelectronics Srl, I-95121 Catania, Italy. (email: francesco.pintacuda@st.com) silicon-based power devices. Above device-specific bias voltage levels, silicon-based power devices, such as power MOSFETs, typically experience directly catastrophic failure, either Single Event Gate Rupture (SEGR) or Single Event Burnout (SEB). However, Schottky devices, made of SiC [3], $\mathrm{Si}$ [6], and GaN [7]-[9], have been reported to exhibit gradual degradation under heavy-ion exposure. SiC Schottky devices also undergo catastrophic SEB when the bias level during irradiation is sufficiently high [1], [3].

This paper concentrates on the heavy-ion induced parametric degradation in SiC Schottky diodes. The gradual degradation observed in these devices makes it difficult to assess their radiation survivability, and to estimate their reliability in radiation environments. For this reason space agencies are cautious in implementing $\mathrm{SiC}$ devices in their space systems [4], [5]. Also at ground level, $\mathrm{SiC}$ power devices can exhibit radiation-induced failures due to cosmic rays [10], [11].

Heavy ion-induced leakage current degradation of a $\mathrm{SiC}$ Schottky diode modifies its entire reverse current-voltage characteristic, while no degradation is observed in the forward characteristics. This paper discusses the charge transport mechanisms (current-voltage characteristics) in the damaged $\mathrm{SiC}$ structure caused by heavy ions. It is found that the charge transport is governed by space charge-limited flow. A macro model is proposed, which can be used to describe the heavyion modified electrical characteristics of SiC Schottky diodes.

\section{EXPERIMENTAL METHODS}

The devices used in this study were commercial $\mathrm{SiC}$ Schottky power diodes manufactured by STMicroelectronics. The devices and their characteristics are given in Table 1. The active areas for the diodes have been estimated from micrographs. The ion beams and their characteristics are tabulated in Table 2. The diodes were decapsulated prior to the irradiation tests to enable the heavy ions to penetrate the sensitive layers in the device, i.e., the Schottky junction and the epitaxial layer. 
Table 1. The characteristics of the studied Schottky diodes. Devices are manufactured by STMicroelectronics.

\begin{tabular}{l|ccc}
\hline Part number & $\boldsymbol{V}_{\boldsymbol{R} \boldsymbol{M} \boldsymbol{M}}$ & $\boldsymbol{I}_{\boldsymbol{F}(\boldsymbol{a v})}$ & Active area \\
\hline STPSC1006D & $600 \mathrm{~V}$ & $10 \mathrm{~A}$ & $2.3 \mathrm{~mm}^{2}$ \\
STPSC10H065DY & $650 \mathrm{~V}$ & $10 \mathrm{~A}$ & $2.6 \mathrm{~mm}^{2}$ \\
\hline
\end{tabular}

The total thickness of overlaying passivation layers and the epitaxial layer was estimated to be of the order of ten micrometers. Hence, the projected ranges for the ions used in this work, as described in Table 2, are sufficient to penetrate the active region.

The heavy-ion irradiations for this work were performed at the RADiation Effects Facility (RADEF) in the Accelerator Laboratory of the University of Jyväskylä [12]. All the irradiations were performed at room temperature (RT) and in vacuum conditions and all the device characterization was done at room temperature. All the ion beams were at normal incidence to the device surface. The ion flux ranged between 20 and $6 \cdot 10^{5} \mathrm{~cm}^{-2} \cdot \mathrm{s}^{-1}$ and cumulative fluences for each irradiation run varied from $10^{3}$ to $10^{7} \mathrm{~cm}^{-2}$.

Table 2. Characteristics of the used ion beams at RADEF facility. The values for LET and projected range are estimated using code from [13], described in [14].

\begin{tabular}{|c|c|c|c|}
\hline ION & $\begin{array}{c}\text { ENERGY } \\
{[\mathrm{MeV}]}\end{array}$ & $\begin{array}{c}\operatorname{LET}(\mathrm{SiC}) \\
{\left[\mathrm{MeV} /\left(\mathrm{mg} / \mathrm{cm}^{2}\right)\right]}\end{array}$ & $\begin{array}{c}\text { Projected } \\
\text { Range } \\
{[\mu \mathrm{m}]}\end{array}$ \\
\hline $\mathrm{Xe}$ & 1217 & 62.4 & 60 \\
\hline $\mathrm{Kr}$ & 768 & 33.8 & 63 \\
\hline
\end{tabular}

The current-voltage characteristics for the devices were measured both for the forward and the reverse voltages, before and after each irradiation run. During the irradiations the device under test (DUT) was biased at fixed reverse voltage and the leakage current was monitored. During heavy-ion tests the biasing and device characterization was done by using a Keithley 2636 SourceMeter [15]. The voltage limit for the 2636 unit is $200 \mathrm{~V}$, which limited the measurement voltages during the irradiations. All the data after annealing, both at room and at high temperature, were obtained by using a Keithley 2410 high-voltage SourceMeter [16]. The voltage limit for the 2410 unit is $1100 \mathrm{~V}$. Because the bare surface of the die was exposed, the voltage levels in the annealing studies were limited by sparking, which occurred approximately at $-400 \mathrm{~V}$.

\section{RESUlts}

The heavy-ion exposure causes an increase in reverse leakage current in the diodes. This effect was first reported in [3]. The effect is illustrated in Figure 1, where the evolution of leakage current during Xe-ion exposure is given for several different biasing configurations for STPSC1006D diodes. The response in STPSC10H065DY diodes was similar. At higher reverse biases during exposure, the linear dependence of leakage current on ion fluence $(\Phi)$ is clearly visible. The data in this plot were obtained for three different individual devices. The data for bias voltages between $-100 \mathrm{~V}$ and $-150 \mathrm{~V}$ were obtained from one device, and data for biases of $-180 \mathrm{~V}$ and $-200 \mathrm{~V}$ were obtained for two separate devices. In order for this gradual degradation to take place the bias voltage has to exceed a certain threshold, which in this case lies between $-130 \mathrm{~V}$ and $-140 \mathrm{~V}$.

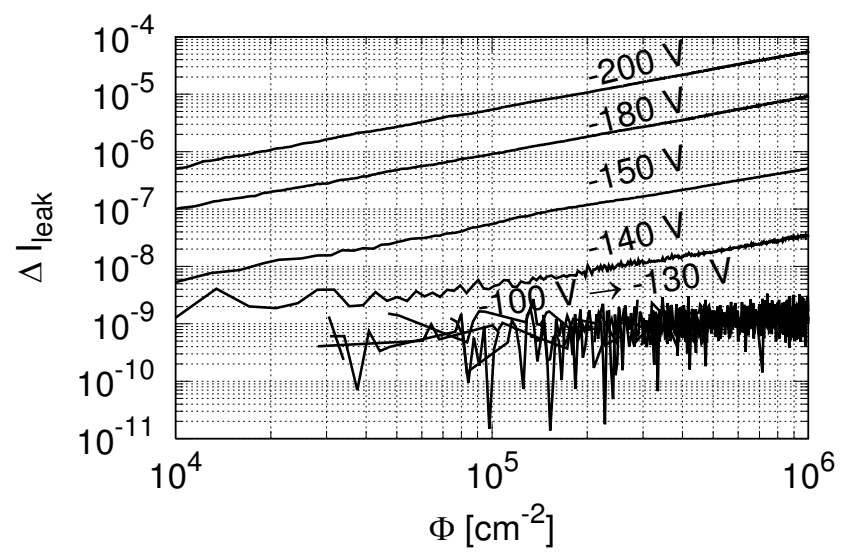

Figure 1. Leakage current evolution in STPSC1006D devices as a function of $X e$ ion fluence at different irradiation bias voltages. The current was monitored throughout the exposure, so the measurement bias and irradiation bias are the same.
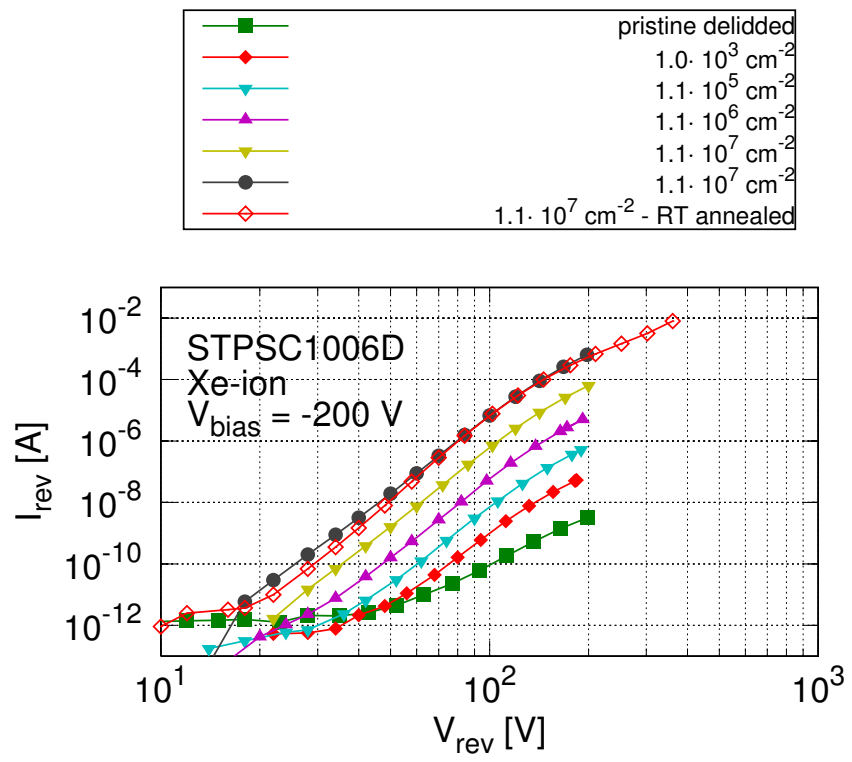

Figure 2. Reverse current-voltage characteristics for a STPSC1006D diode before and after exposure to Xe ions at a bias of $-200 \mathrm{~V}$. Room temperature (RT) annealed data was taken 3 months after the heavy-ion exposure.

Figure 2 plots the reverse current-voltage data, taken before and after each irradiation run, for a diode exposed to Xe ions at a reverse bias of $-200 \mathrm{~V}$ during irradiation. These data show gradual evolution in the entire current-voltage curve with increasing ion fluence. The graph also gives data for the same device after three months of room temperature annealing, showing very little change. This shows that the induced damage is very persistent. The annealing was also checked at elevated temperatures (not shown in the figure), by applying 
$1.7 \mathrm{~V}$ forward bias, corresponding to $1.8 \mathrm{~W}$ of power, to the diode for 24 hours. No observable annealing was found. (The actual junction temperature was not known for this biasing condition.)

The forward current-voltage curves for the same device as in Figure 2 are presented in Figure 3. Notice that the forward characteristics of these diodes were not affected significantly even at fluence levels as high as $10^{7}$ ions $\cdot \mathrm{cm}^{-2}$.

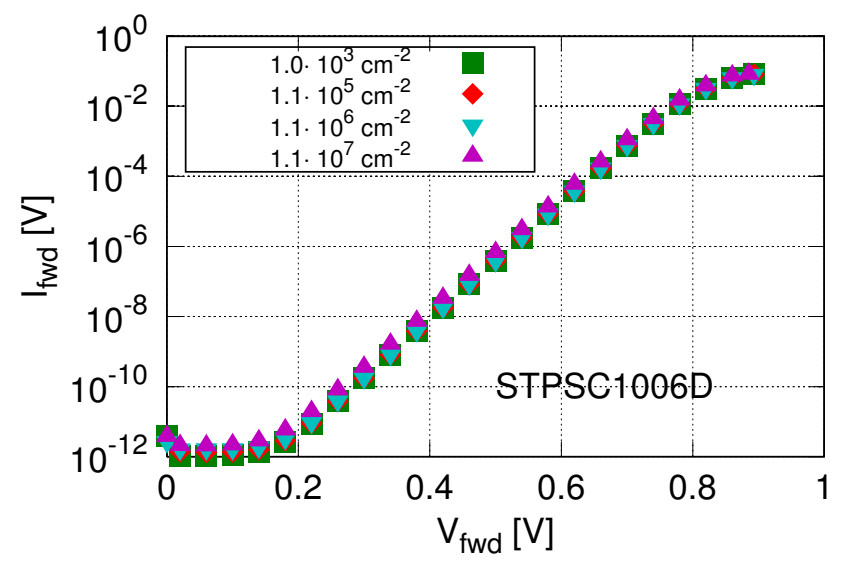

Figure 3. Forward current-voltage characteristics at several exposure levels for a STPSC1006D diode irradiated with Xe-ions at a bias of $-200 \mathrm{~V}$.

\section{CURRENT TRANSPORT IN HEAVY-ION DAMAgED SiC SCHOTTKY JUNCTION}

It was observed that the entire reverse current curve moves higher with increasing ion fluence, as shown in Figure 2. This can also be illustrated by dividing the current for each dataset by the corresponding cumulative ion fluence to obtain a degradation rate.

\begin{tabular}{|c|c|}
\hline 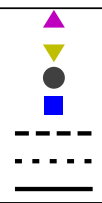 & $\begin{array}{r}1.1 \cdot 10^{5} \text { ions } / \mathrm{cm}^{2} \\
1.1 \cdot 10^{6} \text { ions } / \mathrm{cm}^{2} \\
1.1 \cdot 10^{7} \text { ions } / \mathrm{cm}^{2} \\
1.1 \cdot 10^{7} \text { ions } / \mathrm{cm}^{2}-\mathrm{RT} \text { annealed } \\
\mathrm{I} / \Phi=\mathrm{k}_{1}{ }^{*} \mathrm{~V}^{n} \\
\mathrm{I} \Phi=\mathrm{k}_{2}{ }^{*} \mathrm{~V}^{3 / 2} \\
\mathrm{I} / \Phi=\mathrm{k}_{1}{ }^{*}\left[\mathrm{~V}-\left((\mathrm{I} / \Phi) / \mathrm{k}_{2}\right)^{2 / 3}\right]^{n}\end{array}$ \\
\hline
\end{tabular}

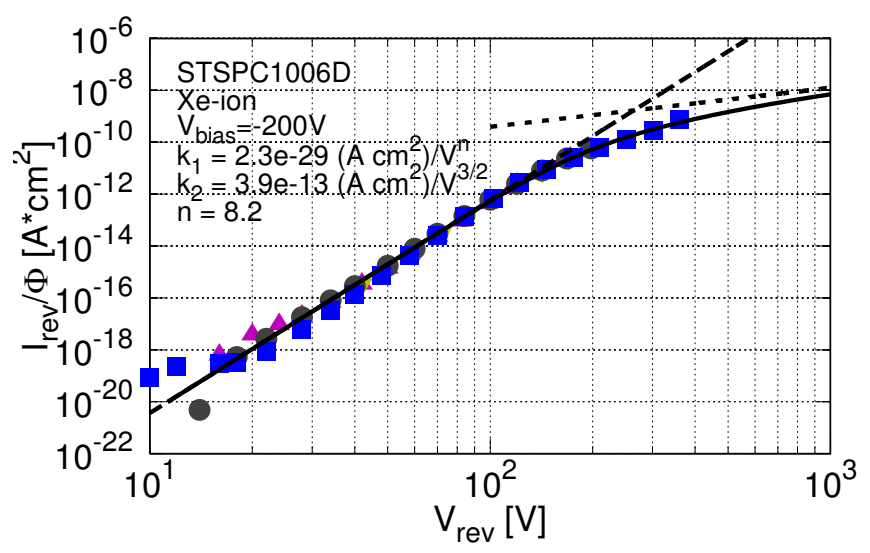

Figure 4. Reverse current-voltage characteristics normalized with the cumulative ion fluence for STPSC1006D diode, irradiated by Xe ions with applied bias voltage of $-200 \mathrm{~V}$. The solid line represents the model described in Eq.(3). Dashed and dotted lines are determined by Eqs. (1) and (2), respectively.
These data are presented in Figure 4, where the data from Figure 2 are normalized with the corresponding cumulative fluence levels. Here, one can see that the entire current-voltage curve is linearly dependent on the fluence. For lower values of fluence the current values deviate from the rest of the dataset since the increase in leakage current is relatively small and the reverse current at low voltages does not rise above the noise floor.

The same effect in the current-voltage characteristics was observed when diodes were irradiated with $\mathrm{Kr}$ ions. Correspondingly, the $\mathrm{Kr}$ ion data, obtained at a reverse bias of $200 \mathrm{~V}$, are presented in Figure 5. The other device type STPSC10H065DY exhibited very similar characteristics after heavy-ion exposure. The graphs in Figure 4 and Figure 5 also present data extracted from the proposed model, which is discussed below.
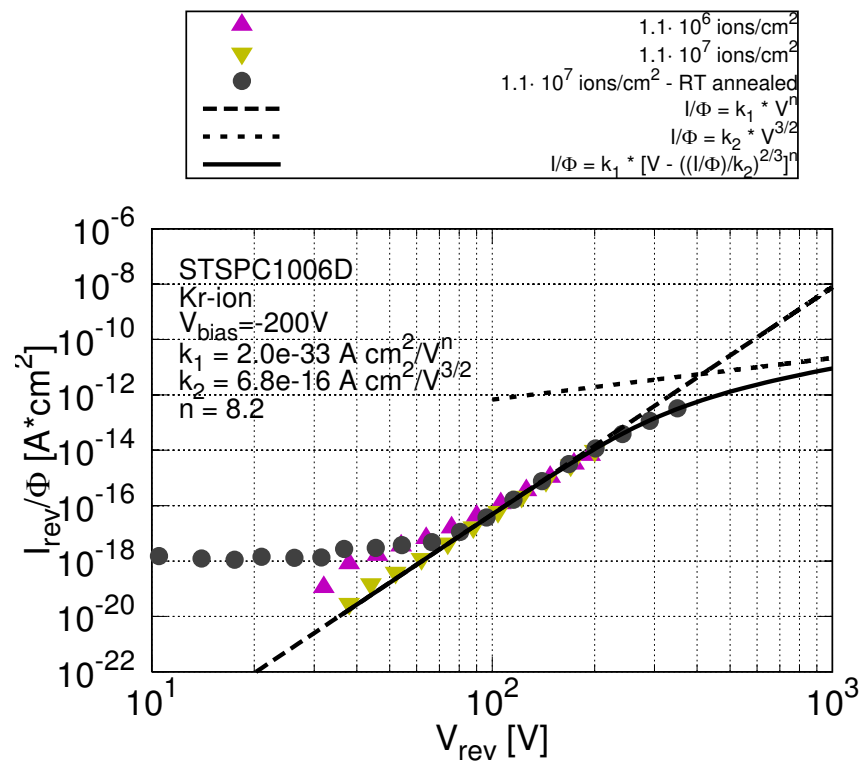

Figure 5. Reverse current-voltage characteristics normalized with the cumulative ion fluence for a STPSC1006D diode irradiated with $\mathrm{Kr}$ ions with applied bias voltage of $-200 \mathrm{~V}$. The deviation of the lower fluence data from the rest at low voltages is partly due to the noise level in the current measurement, but also due to the smaller effect the $\mathrm{Kr}$ ions at this irradiation bias have on the leakage current.

The ion-modified current-voltage characteristics have distinct features for both $\mathrm{Kr}$ and $\mathrm{Xe}$ ions. First, at low voltages the current exhibits a strong power-law behavior, and at higher voltages the current approaches $I \propto V^{3 / 2}$.

At an energy of about $10 \mathrm{MeV} / \mathrm{u}$ a single ion deposits, on average, the bulk of its energy within a radius of tens of nanometers from its trajectory, leaving the rest of the device structure intact. In the test conditions in this work, the number of ion hits in the device active area is relatively small. The fluence levels from $10^{3}$ to $10^{7}$ ions $/ \mathrm{cm}^{2}$ correspond to average distances of $300 \mu \mathrm{m}$ to $3 \mu \mathrm{m}$ between the centers of the damaged sites, respectively. The ion fluences used this work are very low in comparison with the typical fluences used in the ion implantation for termination structures[17]. Hence, it is unlikely that the function of the diode termination 
structures (shaping the voltage contours) is affected by the heavy ion exposure in this work. Moreover, the number of incremental steps observed in the leakage current at low ion fluxes correlates with the active diode area. All this suggests that the degradation occurs in the active region of the diode.

In [18] it is discussed that the heat spike, induced by the heavy ion and the bias, can extend up to a few micrometers from the ion's trajectory, but the possible material melting would occur only within some tens of nanometers from the trajectory. According to [18], the melting is considered to be the primary cause for the degradation. Hence, in the first order approximation, the heavy-ion induced leakage paths can be viewed as separate components parallel to the pristine Schottky structure. The proposed macro model is illustrated in Figure 6, where the ion-induced part is depicted as two voltage-controlled-current-sources (VCCS) in series, which is placed in parallel with a pristine or un-irradiated Schottky structure.

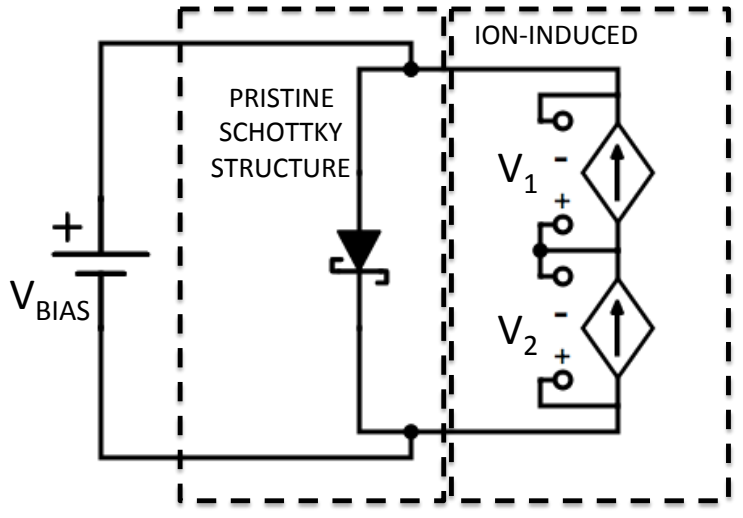

Figure 6. Schematic layout of the heavy-ion induced VCCSs parallel to a pristine Schottky structure.

The number of the ion-induced VCCSs is assumed to increase linearly with increasing ion exposure. In other words, on average, each ion hitting the device is assumed to create a leakage path, which is represented by these parallel VCCSs. It is assumed that the current in the pristine Schottky structure remains much lower compared to the damaged region induced by the ions. Hence, the reverse current is governed by the conduction set by the VCCSs.

The first VCCS is described by a power law

$$
\frac{I}{\Phi}=k_{1} V_{1}^{n}
$$

where $k_{1}$ and $n$ are fitting parameters. At higher reverse voltages the current deviates from this power-law. At these voltages the second VCCS starts to govern the current flow. This part is described by

$$
\frac{I}{\Phi}=k_{2} V_{2}^{3 / 2}
$$

where again $k_{2}$ is a fitting parameter. Now, the overall reverse current in the diode, after an ion exposure, can be given as

$$
I=\Phi \cdot k_{1}\left[V_{B I A S}-\left(\frac{I / \Phi}{k_{2}}\right)^{2 / 3}\right]^{n},
$$

where $V_{B I A S}=V_{1}+V_{2}$ is the total voltage applied across the diode.

It was found that for all the measured current-voltage data, for both device types, the parameter $n$ has an average value of $8.2 \pm 0.4$. This value was used in the analysis to determine the rest of the fitting parameters, $k_{1}$ and $k_{2}$. In order to illustrate the applicability of the proposed model, Figure 4 and Figure 5 present the data derived from Eqs. (1), (2) and (3).

All the obtained parameters are given in Table 3 . There are some differences in the fitting parameters for the two studied devices. These differences can be partly attributed to the difference in the device active area. Also, the different thickness of the epilayer, which is unknown for these devices, could cause differences in the parameter values as it determines the electric field in the SiC below the Schottky junction.

Table 3. Macro model parameters for different ions and device

\begin{tabular}{|c|c|c|c|c|}
\hline & ion & $\begin{array}{c}\text { irrad. } \\
\text { bias }\end{array}$ & $\begin{array}{c}\boldsymbol{k}_{\mathbf{1}} \\
{\left[A \cdot \mathrm{cm}^{2} \cdot V^{-n}\right]}\end{array}$ & $\begin{array}{c}\boldsymbol{k}_{2} \\
{\left[A \cdot \mathrm{cm}^{2} \cdot V^{-3 / 2}\right]}\end{array}$ \\
\hline \multirow{4}{*}{ 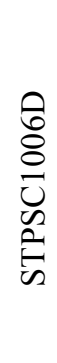 } & $\mathrm{Xe}$ & -200 & $2.3 \cdot 10^{-29}$ & $3.9 \cdot 10^{-13}$ \\
\hline & $\mathrm{Xe}$ & -180 & $4.5 \cdot 10^{-30}$ & $2.2 \cdot 10^{-13}$ \\
\hline & $\mathrm{Xe}$ & -160 & $7.6 \cdot 10^{-31}$ & $2.7 \cdot 10^{-13}$ \\
\hline & $\mathrm{Kr}$ & -200 & $2.0 \cdot 10^{-33}$ & $6.8 \cdot 10^{-16}$ \\
\hline 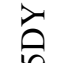 & $\mathrm{Xe}$ & -200 & $2.9 \cdot 10^{-29}$ & $1.4 \cdot 10^{-13}$ \\
\hline 票 & $\mathrm{Xe}$ & -180 & $5.8 \cdot 10^{-30}$ & $1.1 \cdot 10^{-13}$ \\
\hline 空 & $\mathrm{Kr}$ & -200 & $3.3 \cdot 10^{-33}$ & $3.7 \cdot 10^{-16}$ \\
\hline
\end{tabular}
types at different bias conditions. Parameter $n=8.2 \pm 0.4$ in all cases.

\section{DISCUSSION}

The power-law given by Eq.(1) strongly suggests that the current transport in the damaged region is due to spacecharge-limited-conduction (SCLC), described in [19]. The value for the parameter $n=8.2$ determines the energy distribution of the traps, $n_{t}$, in the SiC energy bandgap in the region damaged by the heavy ions. According to [19], when the traps are exponentially distributed in the bandgap as a function of energy, $E$, measured from the bottom of the $\mathrm{SiC}$ conduction band (CB), it gives $n_{t} \propto \exp \left(-E / k T_{c}\right)$. Thus, the SCLC will be described by $I \propto V^{\frac{T C}{T}+1}$. Here $T_{c}$ is a characteristic temperature for the trap distribution and $T$ is the ambient device temperature. High values of $T_{c}$ would make the trap distribution slowly varying with energy. In this case, $T_{c}=(n-1) \cdot T=7.2 \cdot 300 \mathrm{~K}=2160 \mathrm{~K}$, which can be considered as a high value. The trap distribution in the damaged SiC Schottky junction is illustrated in Figure 7. In 
this graph the color gradient represents the exponentially varying trap distribution in the band gap of SiC. Trap densities are the highest near the $\mathrm{CB}$, and exponentially decaying with energy below $\mathrm{CB}$.

The expression in Eq. (2) corresponds to ballistic transport, which is also known as the Child-Langmuir law, or the threehalves law, which determines the maximum current in SCLC [20] in a scatter-free environment. The data clearly show that the leakage current starts to approach this limit at higher voltages.

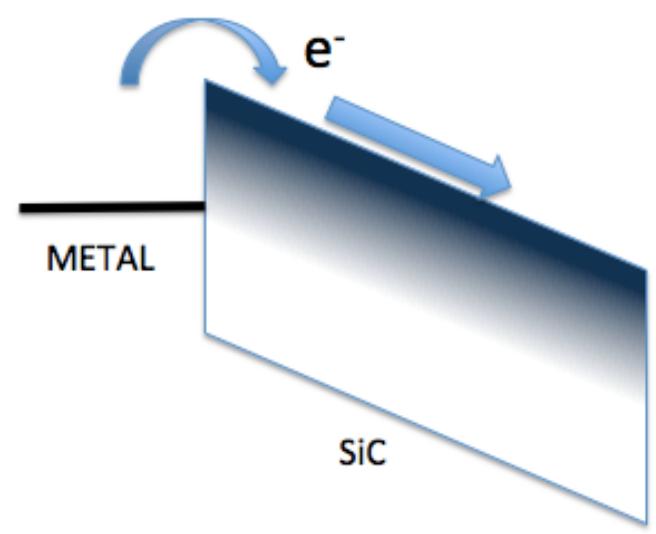

Figure 7. Band diagram for Schottky junction with traps. Variation in trap density is illustrated by the color gradient. Darker color corresponds to higher trap density.

As seen in Figure 4 and Figure 5, this macro model provides a good description of the current-voltage characteristics of the Schottky diode after heavy-ion exposure. The schematic model, depicted in Figure 6, could be used in circuit simulations by applying Eqs. (1) and (2) in it, to estimate overall systems' response under ion exposure for space applications. The parameters $k_{1}$ and $k_{2}$, obtained for Eq.(3), are determined by the device characteristics, such as the size of the active diode area. Also the parameter $n$ can depend on characteristics such as the Schottky metal and the doping levels in the SiC.

\section{CONCLUSIONS}

This work shows that the static electrical characteristics of SiC Schottky power diodes, which are degraded by heavy-ion exposure, can be modeled by using a simple macro model. The proposed model assumes the heavy-ion induced leakage paths to be governed by SCLC mechanisms. These damaged regions can be viewed as separate nonlinear components parallel to the undisturbed $\mathrm{SiC}$ Schottky diode structure. The exact parameterization of the model depends on the characteristics of the individual device type. Hence, device characterization by using ground testing with heavy ions is required in order to utilize this model.

Moreover, due to high current requirements, SiC Schottky power devices can have relatively thick bonding wires shadowing the die. At beam energies, used in typical ground testing, scattering from the bonding wires may play a role in the device response. Hence, in order to get a more detailed picture of heavy-ion induced damage in SiC Schottky power diodes one would need to consider also the testing conditions as discussed in [21].

The current data do not show any signs of latent defects affecting the long-term reliability of heavy-ion exposed $\mathrm{SiC}$ Schottky diodes. However, these data are very limited and should be verified in dedicated experiments in order to fully conclude how the degradation affects the device reliability.

\section{ACKNOWLEDGMENT}

The authors would like to thank Professors Dan Fleetwood, Sokrates Pantelides, Timothy Holman and En Xia Zhang from Vanderbilt University for useful discussions. Also the help from Dr. Heikki Kettunen, Mikko Rossi and Jukka Jaatinen at the RADEF facility is gratefully acknowledged.

\section{REFERENCES}

[2] E. Mizuta, S. Kuboyama, H. Abe, Y. Iwata, and T. Tamura, "Investigation of Single-Event Damages on Silicon Carbide ( $\mathrm{SiC})$ Power MOSFETs," IEEE Trans. Nucl. Sci., vol. 61, no. 4, pp. 1924-1928, Aug. 2014.

[3] S. Kuboyama, C. Kamezawa, N. Ikeda, T. Hirao, and H. Ohyama, "Anomalous Charge Collection in Silicon Carbide Schottky Barrier Diodes and Resulting Permanent Damage and Single-Event Burnout," IEEE Trans. Nucl. Sci., vol. 53, no. 6, pp. 3343-3348, Dec. 2006.

[4] J.-M. Lauenstein, M. C. Casey, K. A. LaBel, S. Ikpe, A. D. Topper, E. P. Wilcox, H. Kim, and A. M. Phan, "SiC - Radiation Update," NASA Electron. Parts Packag. - Electron. Technol. Work., 2015.

[5] J.-M. Lauenstein, M. C. Casey, A. D. Topper, E. P. Wilcox, A. M. Phan, and K. A. LaBel, "Silicon Carbide Power Device Performance Under Heavy-Ion Irradiation," NSREC Conf. Present., 2015.

[6] M. C. Casey, J.-M. Lauenstein, R. L. Ladbury, E. P. Wilcox, A. D. Topper, and K. A. LaBel, "Schottky Diode Derating for Survivability in a Heavy Ion Environment," IEEE Trans. Nucl. Sci., vol. 62, no. 6, pp. 2482-2489, Dec. 2015.

[7] B. D. Olson, J. D. Ingalls, C. H. Rice, C. C. Hedge, P. L. Cole, A. R. Duncan, and S. E. Armstrong, "Leakage Current Degradation of Gallium Nitride Transistors Due to Heavy Ion Tests," in 2015 IEEE Radiation Effects Data Workshop (REDW), 2015, pp. $1-10$.

[8] S. E. Armstrong, K. Bole, H. Bradley, E. Johnson, J. Staggs, W. Shedd, P. L. Cole, C. H. Rice, J. D. Ingalls, C. C. Hedge, A. R. Duncan, and B. D. Olson, "Heavy Ion Testing of Commercial GaN Transistors in the Radio Frequency Spectrum," in 2015 IEEE Radiation Effects Data Workshop (REDW), 2015, pp. 1-6. 
[9] S. Kuboyama, A. Maru, H. Shindou, N. Ikeda, T. Hirao, H. Abe, and T. Tamura, "Single-Event Damages Caused by Heavy Ions Observed in AlGaN/GaN HEMTs," IEEE Trans. Nucl. Sci., vol. 58, no. 6, pp. 2734-2738, Dec. 2011.

[10] H. Asai, K. Sugimoto, I. Nashiyama, Y. Iide, K. Shiba, M. Matsuda, and Y. Miyazaki, "Terrestrial Neutron-Induced Single-Event Burnout in $\mathrm{SiC}$ Power Diodes," IEEE Trans. Nucl. Sci., vol. 59, no. 4, pp. 880-885, Aug. 2012.

[11] H. Asai, I. Nashiyama, K. Sugimoto, K. Shiba, Y. Sakaide, Y. Ishimaru, Y. Okazaki, K. Noguchi, and T. Morimura, "Tolerance Against Terrestrial NeutronInduced Single-Event Burnout in SiC MOSFETs," IEEE Trans. Nucl. Sci., vol. 61, no. 6, pp. 3109-3114, Dec. 2014.

[12] A. Virtanen, H. Kettunen, A. Javanainen, M. Rossi, and J. Jaatinen, "RADiation Effects Facility at JYFL." [Online]. Available: http://www.jyu.fi/accelerator/radef.

[13] A. Javanainen, "European Component Irradiation Facilities Cocktail Calculator," 2015. [Online]. Available: http://research.jyu.fi/radef/ECIFcalc/.

[14] A. Javanainen, "A simple expression for electronic stopping force of heavy ions in solids," Nucl. Instruments Methods Phys. Res. Sect. B Beam Interact. with Mater. Atoms, vol. 285, pp. 158-161, 2012.

[15] Keithley/Tektronix, "Keithley 2600 Series," Keithley Datasheets. [Online]. Available:

http://www.tek.com/sites/tek.com/files/media/media/r
esources/Series2600B_DataSheet.pdf.

[16] Keithley/Tektronix, "Keithley 2400 Series," Keithley

Datasheets. [Online]. Available:

http://www.tek.com/sites/tek.com/files/media/media/r esources/Ser2400.pdf.

[17] A. Itoh, T. Kimoto, and H. Matsunami, "Excellent reverse blocking characteristics of high-voltage $4 \mathrm{H}-$ SiC Schottky rectifiers with boron-implanted edge termination," IEEE Electron Device Lett., vol. 17, no. 3, pp. 139-141, Mar. 1996.

[18] C. Abbate, G. Busatto, P. Cova, N. Delmonte, F. Giuliani, F. Iannuzzo, A. Sanseverino, and F. Velardi, "Analysis of Heavy Ion Irradiation Induced Thermal Damage in SiC Schottky Diodes," IEEE Trans. Nucl. Sci., vol. 62, no. 1, pp. 202-209, Feb. 2015.

[19] A. Rose, "Space-Charge-Limited Currents in Solids," Phys. Rev., vol. 97, no. 6, pp. 1538-1544, Mar. 1955.

[20] C. D. Child, "Discharge From Hot CaO," Phys. Rev. (Series I), vol. 32, no. 5, pp. 492-511, May 1911.

[21] V. Ferlet-Cavrois, J. R. Schwank, S. Liu, M. Muschitiello, T. Beutier, A. Javanainen, A. Hedlund, C. Poivey, A. Mohammadzadeh, R. Harboe-Sorensen, G. Santin, B. Nickson, A. Menicucci, C. Binois, D. Peyre, S. K. Hoeffgen, S. Metzger, D. Schardt, H. Kettunen, A. Virtanen, G. Berger, B. Piquet, J.-C. Foy, M. Zafrani, P. Truscott, M. Poizat, and F. Bezerra, "Influence of Beam Conditions and Energy for SEE Testing," IEEE Trans. Nucl. Sci., vol. 59, no. 4, pp. 1149-1160, Aug. 2012. 